\title{
Analysis of cannabinoids in oral fluid by liquid chromatography-tandem mass spectrometry
}

\author{
Marie Fabritius - Christian Staub - Patrice Mangin • \\ Christian Giroud
}

Received: 9 July 2012/Accepted: 14 October 2012/Published online: 20 November 2012

(C) Japanese Association of Forensic Toxicology and Springer Japan 2012

\begin{abstract}
A sensitive method was developed for quantifying a wide range of cannabinoids in oral fluid (OF) by liquid chromatography-tandem mass spectrometry (LC-MS/MS). These cannabinoids include $\Delta^{9}$-tetrahydrocannabinol (THC), 11-hydroxy- $\Delta^{9}$-tetrahydrocannabinol (11-OH-THC), 11-nor9-carboxy- $\Delta$-tetrahydrocannabinol (THCCOOH), cannabinol (CBN), cannabidiol (CBD), $\Delta^{9}$-tetrahydrocannabinolic acid A (THC-A), 11-nor-9-carboxy- $\Delta^{9}$-tetrahydrocannabinol glucuronide (THCCOOH-gluc), and $\Delta^{9}$-tetrahydrocannabinol glucuronide (THC-gluc). Samples were collected using a Quantisal $^{\mathrm{TM}}$ device. The advantages of performing a liquidliquid extraction (LLE) of KCl-saturated OF using heptane/ ethyl acetate versus a solid-phase extraction (SPE) using HLB copolymer columns were determined. Chromatographic separation was achieved in 11.5 min on a Kinetex ${ }^{\mathrm{TM}}$ column packed with $2.6-\mu \mathrm{m}$ core-shell particles. Both positive (THC, 11-OH-THC, CBN, and CBD) and negative (THCCOOH, THC-gluc, THCCOOH-gluc, and THC-A) electrospray ionization modes were employed with multiple reaction monitoring using a high-end AB Sciex API $5000^{\mathrm{TM}}$ triple quadrupole LC-MS/MS system. Unlike SPE, LLE failed to extract THC-gluc and THCCOOH-gluc. However, the LLE method was more sensitive for the detection of THCCOOH than the SPE method, wherein the limit of detection (LOD) and limit of quantification (LOQ) decreased from 100 to $50 \mathrm{pg} / \mathrm{ml}$ and from 500 to $80 \mathrm{pg} / \mathrm{ml}$,
\end{abstract}

M. Fabritius · C. Staub · C. Giroud $(\bowtie)$

Forensic Toxicology and Chemistry Unit,

University Center of Legal Medicine, Rue du Bugnon 21,

1011 Lausanne, Switzerland

e-mail: christian.giroud@chuv.ch

P. Mangin

Unit of Forensic Medicine, University Center of Legal Medicine,

Rue du Bugnon 21, 1011 Lausanne, Switzerland respectively. The two extraction methods were successfully applied to OF samples collected from volunteers before and after they smoked a homemade cannabis joint. High levels of THC were measured soon after smoking, in addition to significant amounts of THC-A. Other cannabinoids were found in low concentrations. Glucuronide conjugate levels were lower than the method's LOD for most samples. Incubation studies suggest that glucuronides could be enzymatically degraded by glucuronidase prior to OF collection.

Keywords Tetrahydrocannabinol - Cannabinoids · Oral fluid $\cdot$ Saliva $\cdot$ Tandem mass spectrometry · Beta-glucuronidase

\section{Introduction}

Cannabis is one of the most widely used illicit drugs in the world. It is often implicated in forensic cases, such as drugaddiction deaths, driving under the influence of drugs, accidents, and others. The major psychoactive constituent of cannabis smoke is $\Delta^{9}$-tetrahydrocannabinol (THC). THC is frequently detected in the blood of drivers involved or killed in traffic accidents or suspected of driving while impaired. Impairment can result in a loss of tracking ability, attention, reaction time, hand-eye coordination, vigilance, and perception of time and distance [1]. Therefore, sensitive and accurate methods for determining whether someone is under the influence of cannabis are necessary. One may also need to determine whether the use of cannabis occurred shortly before a legally significant event. To this end, one approach could be the detection of cannabinoids in oral fluid (OF). OF is a mixture of saliva from the salivary glands, mucosal cells, bacteria, and food debris containing several hydrolysis enzymes. 
THC is sequestered in the oral cavity during cannabis smoking. After smoking, much lower concentrations of THC are transferred from the plasma to the oral fluid [2]. Therefore, the measurement of high levels of THC in OF strongly suggests recent cannabis use and indicates that the smoker is under the influence of cannabis. This assumption can be confirmed with a second-stage blood analysis. The advantages of using OF over other matrices for monitoring cannabis consumption were recently detailed by Choo and Huestis [2]: OF offers noninvasive collection and a reduced risk of adulteration. Furthermore, collection can be performed without medical supervision and is less objectionable to patients. However, there is a significant issue with OF collection for cannabis testing because the drug is known to cause dry mouth, and for this reason, the specimen volume may be limited [3]. Several cannabinoids have been detected in OF, but apart from THC, they have always been found in low concentrations, especially the metabolites of THC. Because THC can also be detected after passive exposure, the detection of THC metabolites (e.g., 11-nor-9-carboxy- $\Delta^{9}$-tetrahydrocannabinol, THCCOOH) indicative of active smoking is of prime importance [4]. Cannabinol $(\mathrm{CBN})$, the primary degradation product of THC, and cannabidiol (CBD), another component of cannabis smoke, have also been detected in OF [5-7]. The incubation of saliva with glucuronidase enzymes resulted in an increase in the concentrations of free cannabinoids, suggesting that significant levels of conjugated metabolites are also present in this matrix. The question of whether $\Delta^{9}$ tetrahydrocannabinolic acid A (THC-A), the pyrolytic precursor of THC, can be used as a marker of active and recent cannabis smoking remains to be answered [8]. Furthermore, it is useful to distinguish between a therapeutic ingestion of THC (e.g., Sativex ${ }^{\circledR}$, Marinol ${ }^{\circledR}$ ) and the inhalation of a cannabis joint. In this context, it has been shown that THC was not detected in OF when capsules of Marinol $^{\circledR}$ were rapidly swallowed [7], however it is unclear if the same applies to capsules that are chewed before being swallowed.

Several methods have been proposed for the analysis of cannabinoids in alternative matrices (bile, meconium) [9-17] as well as in oral fluid [18-28]. To our knowledge, none allows the sensitive quantification of a broad range of molecules, including the acid precursors, metabolites, and the conjugates. The aim of this study was to devise an analytical method for the rapid and unequivocal determination of THC, 11-hydroxy- $\Delta^{9}$-tetrahydrocannabinol (11-OH-THC), THCCOOH, THC-A, CBN, CBD, 11-nor9-carboxy- $\Delta^{9}$-tetrahydrocannabinol glucuronide (THC$\mathrm{COOH}$-gluc), and $\Delta^{9}$-tetrahydrocannabinol glucuronide (THC-gluc) in OF samples by liquid chromatographytandem mass spectrometry (LC-MS/MS). To this end, we used an unconventional Kinetex ${ }^{\mathrm{TM}}[29,30]$ column packed with 2.6- $\mu \mathrm{m}$ core-shell particles coupled with a high-end and sensitive AB Sciex Triple Quadrupole API $5000^{\mathrm{TM}}$ mass spectrometer. Two types of extraction methods-liquidliquid (LLE) and solid-phase (SPE) extraction-were tested with the goal of measuring the free cannabinoids and glucuronide conjugates concentrations and to achieve subnanogram range detection levels. Whatever the conditions tested, the LLE method failed to extract the glucuronide conjugates from the OF collected using the Quantisal ${ }^{\mathrm{TM}}$ device. A more versatile SPE technique was therefore developed to analyze the entire panel of cannabinoids.

\section{Experimental}

Chemicals and materials

THC, 11-OH-THC, THCCOOH, CBN, CBD, THC-A, THCCOOH-gluc, and the internal standards $\mathrm{THC}-d_{3}$, 11-OH-THC- $d_{3}$, and THCCOOH- $d_{9}$ were purchased from Cerilliant (Round Rock, TX, USA). THC-gluc was obtained from ElSohly Laboratories (Oxford, MS, USA). Cannabichromene (CBC) was purchased from BGB Analytik (Boeckten, Switzerland).

Oasis HLB (3 cc/60 mg) extraction cartridges were purchased from Waters (Baden, Switzerland). Acetonitrile $(\mathrm{ACN})$ and methanol $(\mathrm{MeOH})$ were purchased from Sigma-Aldrich (Steinheim, Germany). All other chemicals were puriss grade. Drug-free OF was composed of a mixture of $\mathrm{OF}$ samples obtained by spitting from several coworkers who had fasted and did not consume cannabis.

OF was collected with the Quantisal ${ }^{\mathrm{TM}}$ device (nal von minden GmbH, Regensburg, Germany), which consists of an absorptive cellulose pad mounted on a polypropylene stem. The volume indicator turns blue when an adequate volume $(1.0 \pm 10 \% \mathrm{ml})$ is collected. The pad was then placed into a plastic tube containing $3 \mathrm{ml}$ of buffer. As recommended by the supplier, the tube was capped and left at room temperature overnight and then stored at $-80{ }^{\circ} \mathrm{C}$ prior to analysis. Moore et al. [31] recommended storing the OF samples in the Quantisal ${ }^{\mathrm{TM}}$ collection device under refrigeration to inhibit THC degradation. For better preservation, the Quantisal ${ }^{\mathrm{TM}}$ devices were stored at $-80{ }^{\circ} \mathrm{C}$ prior to analysis.

Preparation of standard solutions

Individual stock solutions of $10 \mu \mathrm{g} / \mathrm{ml} \mathrm{THC}$, THCCOOH, THC-A, CBD, and CBN and $1 \mu \mathrm{g} / \mathrm{ml}$ THCCOOH-gluc, 11-OH-THC, and THC-gluc were diluted with methanol to prepare calibration standards for LLE and SPE methods. Individual intermediate stock solutions containing 200 and 
$10 \mathrm{ng} / \mathrm{ml}$ of each cannabinoid were prepared in methanol and stored at $-20^{\circ} \mathrm{C}$. A specific solution of $\mathrm{THCCOOH}$ was prepared at a concentration of $1 \mathrm{ng} / \mathrm{ml}$ in methanol for the LLE method. In addition, a $2 \mathrm{ng} / \mathrm{ml}$ solution of THC$\mathrm{COOH}-d_{9}$ and a $100 \mathrm{ng} / \mathrm{ml}$ solution of THC- $d_{3}$ and $11-\mathrm{OH}-$ THC- $d_{3}$ were prepared for the LLE method. A 100- $\mu$ l aliquot of the THCCOOH- $d_{9}$ solution and $50 \mu \mathrm{l}$ of the THC- $d_{3}$ and 11-OH-THC- $d_{3}$ solution were added to the Quantisal $^{\mathrm{TM}}$ buffer (final concentrations in the extraction buffer: $50 \mathrm{pg} / \mathrm{ml}$ of $\mathrm{THCCOOH}-d_{9}$ and $1250 \mathrm{pg} / \mathrm{ml}$ of THC- $d_{3}$ and 11-OH-THC- $d_{3}$ ). For the SPE method, an internal standard solution containing $100 \mathrm{ng} / \mathrm{ml}$ of THC- $d_{3}$, $11-\mathrm{OH}-\mathrm{THC}-d_{3}$, and THCCOOH$-d_{9}$ was prepared in methanol. Fifty microliters of this mix was added to the Quantisal $^{\mathrm{TM}}$ collection buffer before extraction (final concentrations $1250 \mathrm{pg} / \mathrm{ml}$ ). THC- $d_{3}$ was utilized for CBN, $\mathrm{CBD}$, and THC-gluc determination, whereas THCCOOH$d_{9}$ was used for the quantification of THC-A and THC$\mathrm{COOH}$-gluc. Other cannabinoids were measured in the presence of their deuterated homologs as internal standards. A specific solution of $100 \mathrm{ng} / \mathrm{ml}$ of CBC was prepared from a standard solution at a concentration of $1 \mu \mathrm{g} / \mathrm{ml}$.

\section{Sample pretreatment}

The maximum volume of absorbed OF was collected by squeezing the cellulose pad from the Quantisal ${ }^{\mathrm{TM}}$ collection device onto the walls of the plastic tube. Subsequently, methanol $(1.5 \mathrm{ml})$ was added to the pad to wash off any residual cannabinoids. The methanolic extract was evaporated to dryness under nitrogen at room temperature. The OF-buffer mixture was added to the methanolic residue and the resulting mixture was sonicated for $5 \mathrm{~min}$. The combined extracts were then purified by liquid-liquid or solid-phase extraction.

\section{Liquid-liquid extraction (LLE)}

A 1.5-ml aliquot of OF combined extracts was mixed with $0.5 \mathrm{ml}$ of ammonium formate buffer $(10 \mathrm{mM}, \mathrm{pH} 6.5)$. Subsequently, potassium chloride was added until the solution became saturated. Samples were extracted with $4 \mathrm{ml}$ of heptane:ethyl acetate $(4: 1, \mathrm{v} / \mathrm{v})$ using a vortex shaker for $1 \mathrm{~min}$, followed by $5 \mathrm{~min}$ on a reciprocating shaker (Edmond Bühler SM-30, GlasKeller, Basel; 180 oscillations/min). After centrifugation at $3000 \mathrm{rpm}$ for $5 \mathrm{~min}$, the organic phase was removed and evaporated to dryness under nitrogen at room temperature. The residue was then dissolved in $100 \mu \mathrm{l}$ of initial mobile phase (70:30, $\mathrm{A}: \mathrm{B}$, see below), vortexed, sonicated for $5 \mathrm{~min}$, and transferred to a $250-\mu \mathrm{l}$ vial for LC-MS/MS analysis.
Solid-phase extraction (SPE)

Oasis HLB extraction columns were conditioned with $2 \mathrm{ml}$ of methanol, $2 \mathrm{ml}$ of deionized water, and $2 \mathrm{ml}$ of ammonium formate buffer (10 mM, pH 6.5). Subsequently, $1.5 \mathrm{ml}$ of combined OF extracts was added to the extraction column and loaded by gravity. The columns were washed with $4 \mathrm{ml}$ of ammonium formate buffer $(10 \mathrm{mM}$, $\mathrm{pH}$ 6.5):methanol (95:5, v/v) and dried under vacuum for $15 \mathrm{~min}$. Cannabinoids were eluted with $3 \mathrm{ml}$ of methanol $(2 \times 1.5 \mathrm{ml})$ and the resulting eluates were evaporated to dryness under a nitrogen stream at room temperature. The residues were reconstituted in $100 \mu \mathrm{l}$ of initial mobile phase, vortexed, sonicated for $5 \mathrm{~min}$, and transferred into $250-\mu 1$ autosampler vials for LC-MS/MS analysis.

\section{Liquid chromatography}

Chromatographic analyses were carried out using a Dionex UltiMate 3000 Rapid Separation LC system equipped with two binary pumps, an autosampler, and a column oven compartment (Thermo Scientific, Olten, Switzerland). A Kinetex $^{\mathrm{TM}}$ C18 100A column $(150 \times 2.1 \mathrm{~mm}$ i.d. $)$ (Phenomenex, Brechbühler, Echallens, Switzerland) packed with core-shell $2.6 \mu \mathrm{m}$ particles was used for the chromatographic separation. The autosampler and column oven temperatures were set to 10 and $40{ }^{\circ} \mathrm{C}$, respectively. A $10-\mu \mathrm{l}$ sample was injected into the LC-MS/MS. Gradient elution was performed using a mixture of (A) ammonium formate buffer ( $5 \mathrm{mM}, \mathrm{pH} 6.8$ ) and (B) acetonitrile at a constant flow rate of $400 \mu \mathrm{l} / \mathrm{min}$. The initial gradient conditions were $30 \%$ $\mathrm{B}$, held for $30 \mathrm{~s}$, and then linearly increased to $90 \% \mathrm{~B}$ over $7 \mathrm{~min}$. The final B concentration was maintained for $2 \mathrm{~min}$. Finally, the proportion of solvent B was reduced from 90 to $30 \%$ over $30 \mathrm{~s}$ and held for $1.5 \mathrm{~min}$. The maximum pressure was set to 600 bar.

\section{Mass spectrometry}

The LC system was coupled to an AB Sciex API 5000 ${ }^{\mathrm{TM}}$ triple quadrupole mass spectrometer interfaced with a Turbo $\mathrm{V}^{\mathrm{TM}}$ source with a TurboIonSpray ${ }^{\circledR}$ probe (ESI). Both positive and negative polarities were employed: $\mathrm{THCCOOH}$, THCCOOH-gluc, THC-gluc, and THC-A were monitored in the negative ionization mode, whereas THC, 11-OH-THC, $\mathrm{CBD}$, and $\mathrm{CBN}$ were monitored in the positive ionization mode. Mass spectrometry transitions were recorded using a scheduled multiple reaction monitoring mode (MRM) with three separate time windows. The first time window (from start to $5.1 \mathrm{~min}$ ) was operated in the negative ionization mode, whereas the second (from 5.1 to $6.4 \mathrm{~min}$ ) and the third (from 6.4 to $7.5 \mathrm{~min}$ ) were operated in the positive mode. The selected ions, MS/MS parameters and retention times are 
Table 1 Selected ion parameters and retention times for cannabinoids in oral fluid

\begin{tabular}{|c|c|c|c|c|c|c|}
\hline Compound name & Precursor ion $(\mathrm{m} / \mathrm{z})$ & Product ions $(\mathrm{m} / \mathrm{z})$ & $\mathrm{DP}(\mathrm{V})$ & $\mathrm{CE}(\mathrm{V})$ & $\mathrm{RT}(\min )$ & $\mathrm{TW}^{\mathrm{a}}$ \\
\hline \multirow[t]{2}{*}{ THCCOOH-gluc } & 519.2 & 343.2 & -25 & -30 & 3.24 & 1 \\
\hline & 519.2 & 299.2 & -25 & -38 & 3.24 & 1 \\
\hline \multirow[t]{2}{*}{ THC-gluc } & 489.0 & 313.2 & -50 & -42 & 3.31 & 1 \\
\hline & 489.0 & 113.2 & -50 & -30 & 3.31 & 1 \\
\hline \multirow[t]{2}{*}{ THC-A } & 357.1 & 313.2 & -35 & -28 & 4.68 & 1 \\
\hline & 357.1 & 245.0 & -35 & -36 & 4.68 & 1 \\
\hline \multirow[t]{2}{*}{ THCCOOH } & 343.2 & 299.2 & -50 & -24 & 4.87 & 1 \\
\hline & 343.2 & 191.1 & -50 & -42 & 4.87 & 1 \\
\hline \multirow[t]{2}{*}{ 11-OH-THC } & 331.3 & 313.2 & 36 & 21 & 5.25 & 2 \\
\hline & 331.3 & 193.1 & 36 & 33 & 5.25 & 2 \\
\hline \multirow[t]{2}{*}{ CBD } & 315.2 & 193.2 & 41 & 29 & 6.13 & 2 \\
\hline & 315.2 & 259.1 & 41 & 25 & 6.13 & 2 \\
\hline \multirow[t]{2}{*}{ CBN } & 311.2 & 223.2 & 51 & 27 & 6.68 & 3 \\
\hline & 311.2 & 178.2 & 51 & 81 & 6.68 & 3 \\
\hline \multirow[t]{2}{*}{ THC } & 315.2 & 193.1 & 41 & 29 & 7.02 & 3 \\
\hline & 315.2 & 259.1 & 41 & 25 & 7.02 & 3 \\
\hline \multirow[t]{2}{*}{ THC- $d_{3}$} & 318.2 & 262.1 & 41 & 25 & 7.00 & 3 \\
\hline & 318.2 & 196.1 & 41 & 31 & 7.00 & 3 \\
\hline \multirow[t]{2}{*}{$11-\mathrm{OH}-\mathrm{THC}-d_{3}$} & 334.3 & 316.0 & 31 & 21 & 5.23 & 2 \\
\hline & 334.3 & 196.0 & 31 & 33 & 5.23 & 2 \\
\hline \multirow[t]{2}{*}{ THCCOOH- $d_{9}$} & 352.2 & 308.1 & -50 & -24 & 4.84 & 1 \\
\hline & 352.2 & 194.2 & -50 & -44 & 4.84 & 1 \\
\hline
\end{tabular}

Boldface denotes quantifier transitions

$D P$ declustering potential, $C E$ collision energy, $R T$ retention time, $T W$ time window

${ }^{\text {a }}$ TW 1 from start to $5.1 \mathrm{~min}$, TW 2 from 5.1 to $6.4 \mathrm{~min}$ and TW 3 from 6.4 to $7.5 \mathrm{~min}$

provided in Table 1. The ion spray voltage was set to $-4500 \mathrm{~V}$ for the negative polarity and $+5500 \mathrm{~V}$ for the positive polarity. The source temperature was set to $550{ }^{\circ} \mathrm{C}$ for both cases. Analyst ${ }^{\circledR} 1.6$ software was used to control the instrument and process the data. A representative reconstructed MRM chromatogram of an OF extract spiked with $50 \mathrm{ng} / \mathrm{ml}$ of each cannabinoid is shown in Fig. 1.

\section{Method validation}

Method validation was performed by establishing linearity, intraday and intermediate precisions, trueness and bias, limit of detection (LOD), limit of quantification (LOQ), extraction recovery, and matrix effects. In addition, the stability of the cannabinoids during storage was assessed. The validation was performed according the Société Française des Sciences et Techniques Pharmaceutiques (SFSTP) recommendations [32, 33].

\section{Sensitivity, limits of detection and quantification}

The LOD was determined in triplicate by injecting a series of drug-fortified human OF extracts in order of decreasing concentration. The LOD was the lowest analyte concentration that exhibited a signal-to-noise $(\mathrm{S} / \mathrm{N})$ ratio of at least 3 and an acceptable chromatographic peak shape. The LOQ was the lowest concentration that exhibited acceptable accuracy and precision [relative standard deviation (RSD) within at least $20 \%, n=4]$.

Linearity, trueness and bias, intraday and intermediate precisions

The linearity of the response function was investigated in the $\mathrm{OF}$ concentration range of $0.5-75 \mathrm{ng} / \mathrm{ml}$ for all cannabinoids, and in the range of $50-500 \mathrm{pg} / \mathrm{ml}$ for THC$\mathrm{COOH}$ with the LLE method. Calibration curves were obtained at eight calibration levels by injecting $0.1,0.5,1$, 5, 10, 25, 50, and $100 \mathrm{ng}(30,50,100,250,500,750,1000$, and $1500 \mathrm{pg}$ of $\mathrm{THCCOOH}$ with LLE) of standards directly onto the pad before adding $1 \mathrm{ml}$ of drug-free OF. Linearity was investigated by calculating the regression using the least-squares method and is expressed as the square of the correlation coefficient $\left(R^{2}\right)$. A weighting factor of $1 / x$ was applied for each compound. Calibration curves obtained on three different days were used to 
Fig. 1 Representative reconstructed MRM chromatogram of an OF sample spiked at a concentration of $50 \mathrm{ng} / \mathrm{ml}$ for each cannabinoid: (1) THCCOOH-gluc 519.2 $\rightarrow$ 343.2, (2) THCCOOH-gluc $519.2 \rightarrow 299.2$, (3) THC-gluc $489.0 \rightarrow 313.2$, (4) THC-gluc $489.0 \rightarrow 113.2$, (5) THC-A $357.1 \rightarrow 313.2,(6)$ THC-A $357.1 \rightarrow 245.0,(7) \mathrm{THCCOOH}$ $343.2 \rightarrow 299.2(8) \mathrm{THCCOOH}$ $343.2 \rightarrow 191.1$, (9) 11-OH-THC $331.3 \rightarrow 313.2$, (10) $11-\mathrm{OH}-$ THC $331.3 \rightarrow 193.1,(11)$ CBD $315.2 \rightarrow 193.2,(12)$ CBD 315.2 $\rightarrow$ 259.1, (13) CBN 311.2

$\rightarrow 223.2,(14) \mathrm{CBN}$

$311.2 \rightarrow 178.2,(15) \mathrm{THC}$

$315.2 \rightarrow 193.2,(16)$ THC 315.2

$\rightarrow$ 259.1. Vertical lines indicate the three time windows (TW). First TW: negative mode. Second and third TW: positive mode

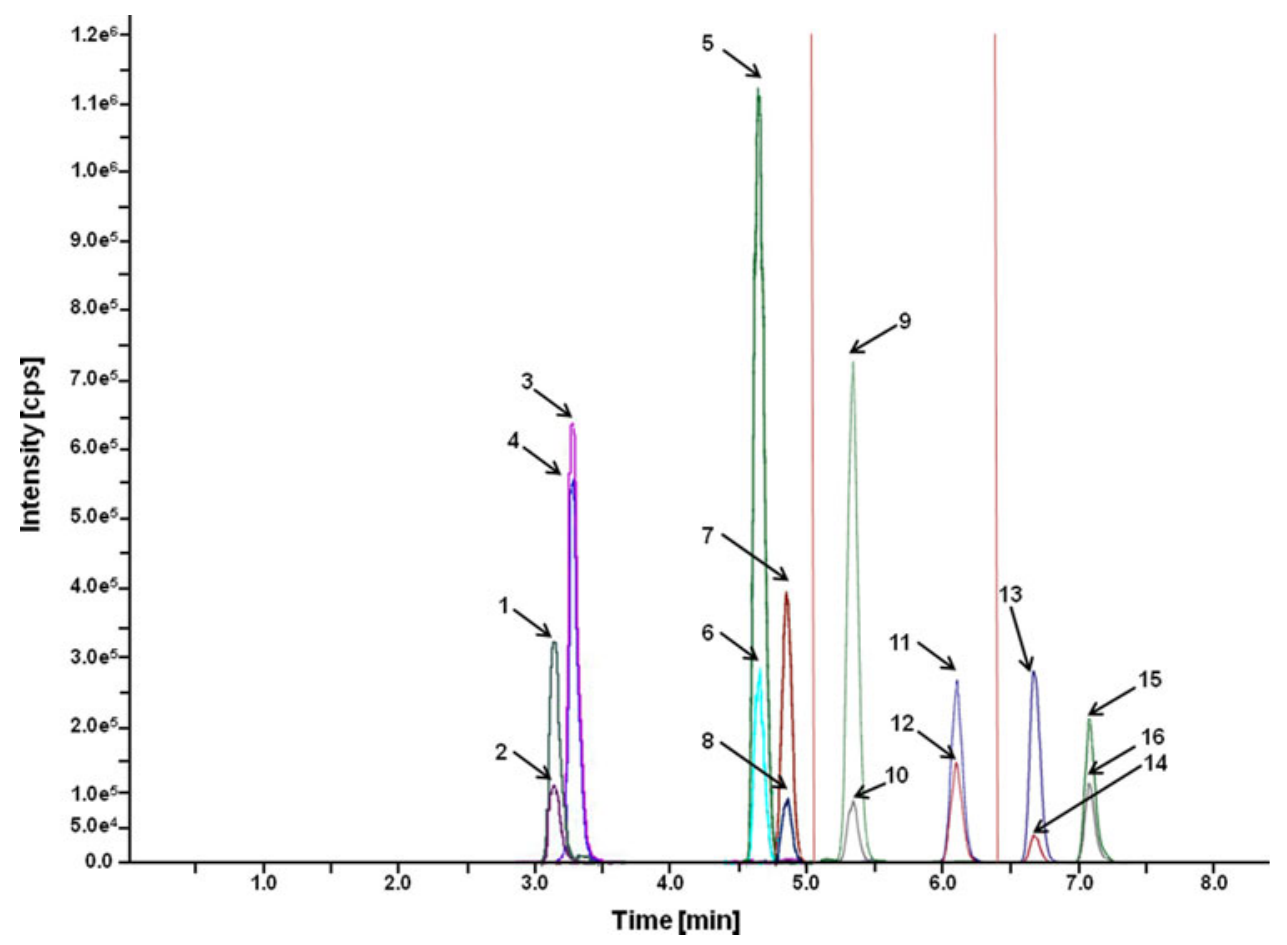

calculate the mean slope, the $y$ intercept, and their variations. Bias and precisions were determined at five concentration levels across the linear dynamic range. The intraday precision was evaluated by analyzing four $\mathrm{OF}$ specimens spiked with $0.5,2,10,30$, and $75 \mathrm{ng} / \mathrm{ml}(50,75$, $100,250,500 \mathrm{pg} / \mathrm{ml}$ for THCCOOH by LLE) concentrations of cannabinoids on the same day. The intermediate precision was assessed by evaluating the same concentration on three separate days. The bias was determined by comparing the mean measured concentration of four analytes with that of the target value and was expressed as a percentage of the target concentration. Acceptable values were within $15 \%$ of the target concentration for the bias and less than $15 \%$ for the coefficients of variation (CVs) of the intraday and intermediate precisions.

Selectivity, interferences, extraction recovery, and matrix effects

Ten blank OF extracts of different sources were analyzed to prove the lack of response in blank matrix. Furthermore, possible interferences were tested with CBC. This cannabinoid, THC, and CBD are characterized by the same mass weight and share a few common ion transitions. It is therefore important that these cannabinoids are well separated from each other. Their unequivocal identification relies on both their ion transitions and their retention time (RT). To disclose any interference, CBC standards were either injected alone or in combination with $\mathrm{CBD}$ and THC standards to compare their RT and to determine whether CBC could interfere with CBD and THC quantitation.

The extraction recoveries and matrix effects were determined for each analyte at low and high concentrations according to the method proposed by Matuszewski et al. [34]. Three batches of OF samples were analyzed: batch A was composed of drug-free OF samples spiked with cannabinoids prior to SPE or LLE; batch B was composed of OF extracts spiked after SPE or LLE; batch C was composed of standard methanolic solutions of cannabinoids. Following analysis by LC-MS/MS, the cannabinoid peak areas were determined. The $\mathrm{A} / \mathrm{B}$ ratio gave the extraction recovery, whereas the $\mathrm{B} / \mathrm{C}$ ratio gave the matrix effect.

\section{Stability studies and carryover}

The stability of OF samples was investigated after one and three freeze-thaw cycles $\left(23 \mathrm{~h}\right.$ freezing at $-80{ }^{\circ} \mathrm{C}$ followed by $1 \mathrm{~h}$ thaw at room temperature). Extracts of $\mathrm{OF}$ samples $(n=4)$ at three fortified concentrations $(2,10$, and $75 \mathrm{ng} / \mathrm{ml}$ of OF) were analyzed before and after one or three freeze-thaw cycles. The response (peak areas) was compared to that of the unfrozen samples (0\% loss) and calculated as a loss percentage.

The stability of cannabinoids at room temperature was also investigated. After OF collection, the collector device was left at room temperature for $1,4,12$, or $24 \mathrm{~h}$ before storage at $-80^{\circ} \mathrm{C}$. The carryover was established by injecting one extract prepared with one OF sample 
containing the highest concentration investigated followed by a blank extract. The carryover was considered insignificant when the peak area was $<20 \%$ of the lower limit of quantification.

Determination of cannabinoids in oral fluid sampled from five volunteers before and after smoking a homemade joint

Five healthy male volunteers between 18 and 30 years of age, all heavy cannabis smokers, participated in the study. Subjects were recruited through advertisements in hospitals and universities. They had no known history of neurological or psychiatric disorders. The inclusion protocol consisted of several distinct steps: during a first interview, we gave detailed explanations about the experimental protocol. Subjects then underwent a thorough medical examination and a psychiatric interview. During this inclusion visit, participants provided a detailed medical history and filled out a questionnaire about their drug use and habits. The mean consumption of cannabis for the 3 months preceding inclusion in the study was set to a minimum of ten joints per month and a maximum of two joints per day.

Subjects were asked to provide several OF specimens before and after smoking a homemade cannabis joint. The sampling of the OF specimens was carried out at home under real-life conditions. The study was approved by the Cantonal Research Ethics Committee (Vaud), and the volunteers were asked to provide their informed consent. All subjects were financially compensated for their participation. One OF sample was collected before smoking the joint, and then five or six were collected afterwards. For practical reasons, the study was terminated $4 \mathrm{~h}$ after the joint was smoked. After collection, the samples were brought to the laboratory and stored at $-80{ }^{\circ} \mathrm{C}$ prior to analysis.

Chemical and enzymatic hydrolysis of glucuronides in $\mathrm{OF}$

Several publications have shown that saliva contains betaglucuronidase enzymes [35-37]. To investigate whether these OF enzymes are able to hydrolyze cannabinoid conjugates, the degree of degradation of two glucuronides was evaluated under various conditions to discriminate between nonenzymatic (chemical) and enzymatic hydrolysis. Hydrolysis was carried out in water or $\mathrm{OF}-$ at the native $\mathrm{OF} \mathrm{pH}(\mathrm{pH}$ 7.0) and also at the optimal $\mathrm{pH}$ for betaglucuronidase activity ( $\mathrm{pH} 4.5$ ). We also assessed the effect of heat inactivation of OF enzymes on the degradation of cannabinoid conjugates. To this end, $300 \mu \mathrm{l}$ of water or acetate buffer $(200 \mathrm{mM}, \mathrm{pH} 4.5)$ was added to $2.5 \mathrm{ml}$ of water, native $\mathrm{OF}$, or inactivated OF (obtained by boiling for $5 \mathrm{~min}$ ). All experiments were repeated three times.
Samples containing THC-gluc and THCCOOH-gluc at concentrations of $5 \mathrm{ng} / \mathrm{ml}$ each were incubated at $37{ }^{\circ} \mathrm{C}$ for up to $5 \mathrm{~h}$. Aliquots were sampled at $t=0,0.5,1$, and $5 \mathrm{~h}$. Solid-phase extraction and LC-MS/MS analysis were carried out according to the developed method.

\section{Results and discussion}

\section{Extraction}

All free unconjugated cannabinoids were detected by both the LLE and SPE methods. However, even after changing the extraction conditions, neither THC-gluc nor THCCOOH-gluc could be detected using the LLE technique. Increasing the polarity of the extracting solvent or adding different salts to the water phase did not significantly increase the recovery of the glucuronide derivatives. Although a higher sensitivity was achieved for $\mathrm{THCCOOH}$ using the LLE approach, the SPE method allowed for the analysis of the glucuronide conjugates. Because each method has its own advantages and limitations, both were validated.

\section{Method validation}

The main validation parameters obtained for the LLE and SPE extraction methods are provided in Tables 2 and 3 , respectively.

\section{Limits of detection and quantification}

The sensitivities of the LLE and SPE methods were estimated by determining the LOD and LOQ values. The concentration that satisfied the validation criteria $(\mathrm{CV}$ $<20 \%$ for the bias and precision values) for the LOQ was $0.5 \mathrm{ng} / \mathrm{ml}$ for all cannabinoids using both extraction methods, except for THCCOOH, which exhibited a LOQ of $0.08 \mathrm{ng} / \mathrm{ml}$ with the LLE method. Moore et al. [4] and Day et al. [21] reported concentrations of $\mathrm{THCCOOH}$ in OF in the range of $5-150 \mathrm{pg} / \mathrm{ml}$, which includes the LOQ value of the LLE method. These concentration thresholds are consistent with the values discussed by Pil and Verstraete [38] in their review of drug testing in oral fluid.

\section{Linearity, trueness and bias, intraday and intermediate} precisions

The range of the standard curves was $0.5-75 \mathrm{ng} / \mathrm{ml}$ for all cannabinoids investigated, with the exception of THC$\mathrm{COOH}$ extracted by LLE, which was $50-500 \mathrm{pg} / \mathrm{ml}$. The $R^{2}$ values (with $1 / x$ weighting) were acceptable for all cannabinoids $\left(R^{2}>0.9943\right)$. Variations in the slopes of all 
Table 2 Validation data for trueness, intraday and intermediate precisions, and linearity for THCCOOH, THC-A, 11-OH-THC, CBD, THC, and $\mathrm{CBN}$ obtained using the liquid-liquid extraction method

\begin{tabular}{|c|c|c|c|c|c|c|c|c|}
\hline Validation criterion & Level $^{\mathrm{a}} \mathrm{a}$ & THCCOOH & Level $^{\mathrm{a}} \mathrm{b}$ & THC-A & 11-OH-THC & CBD & THC & $\mathrm{CBN}$ \\
\hline \multirow[t]{5}{*}{ Trueness $(\%)$} & 0.05 & 119.9 & 0.5 & 104.0 & 114.5 & 108.5 & 108.4 & 108.2 \\
\hline & 0.075 & 109.7 & 2 & 103.7 & 107.8 & 106.3 & 105.9 & 104.0 \\
\hline & 0.1 & 102.8 & 10 & 100.8 & 100.8 & 99.5 & 102.7 & 102.0 \\
\hline & 0.25 & 101.3 & 30 & 103.2 & 98.5 & 98.9 & 100.1 & 99.7 \\
\hline & 0.5 & 99.7 & 75 & 101.4 & 100.4 & 101.4 & 100.0 & 99.8 \\
\hline \multirow[t]{5}{*}{ Intraday precision $(\mathrm{CV}, \%)$} & 0.05 & 57.6 & 0.5 & 14.6 & 7.4 & 9.0 & 7.1 & 7.1 \\
\hline & 0.075 & 13.5 & 2 & 6.5 & 7.0 & 6.4 & 5.1 & 4.7 \\
\hline & 0.1 & 8.3 & 10 & 6.9 & 3.6 & 4.6 & 2.0 & 2.7 \\
\hline & 0.25 & 5.2 & 30 & 5.6 & 4.0 & 3.3 & 1.3 & 1.6 \\
\hline & 0.5 & 4.0 & 75 & 2.0 & 1.9 & 4.7 & 0.4 & 1.4 \\
\hline \multirow{5}{*}{$\begin{array}{l}\text { Intermediate precision } \\
(\mathrm{CV}, \%)\end{array}$} & 0.05 & 45.3 & 0.5 & 14.9 & 9.6 & 10.4 & 7.7 & 14.9 \\
\hline & 0.075 & 17.1 & 2 & 8.0 & 8.5 & 7.8 & 5.6 & 5.4 \\
\hline & 0.1 & 8.3 & 10 & 6.9 & 3.6 & 5.7 & 3.1 & 3.5 \\
\hline & 0.25 & 5.2 & 30 & 5.6 & 4.0 & 3.7 & 1.3 & 2.6 \\
\hline & 0.5 & 4.2 & 75 & 2.2 & 2.2 & 4.7 & 0.8 & 1.4 \\
\hline \multicolumn{9}{|l|}{ Linearity } \\
\hline Slope (CV) & & $\begin{array}{l}0.9964 \\
\quad(2.3 \%)\end{array}$ & & $\begin{array}{l}1.004 \\
(0.5 \%)\end{array}$ & $\begin{array}{l}1.003 \\
(0.2 \%)\end{array}$ & $\begin{array}{l}0.9964 \\
(1.2 \%)\end{array}$ & $\begin{array}{c}1.0029 \\
(0.7 \%)\end{array}$ & $\begin{array}{l}0.9995 \\
\quad(1.1 \%)\end{array}$ \\
\hline$y$ intercept $(\mathrm{CV})$ & & $\begin{array}{l}0.0034 \\
\quad(14.1 \%)\end{array}$ & & $\begin{array}{l}0.0186 \\
\quad(10.1 \%)\end{array}$ & $\begin{array}{l}0.0061 \\
(14.8 \%)\end{array}$ & $\begin{array}{l}0.0148 \\
(10.7 \%)\end{array}$ & $\begin{array}{l}0.0905 \\
\quad(6.0 \%)\end{array}$ & $\begin{array}{l}0.0745 \\
\quad(3.6 \%)\end{array}$ \\
\hline$R^{2}$ & & 0.9943 & & 0.9976 & 0.9994 & 0.9973 & 0.9998 & 0.9995 \\
\hline LOD (ng/ml) & & 0.05 & & 0.3 & 0.2 & 0.3 & 0.3 & 0.3 \\
\hline LOQ (ng/ml) & & 0.08 & & 0.5 & 0.5 & 0.5 & 0.5 & 0.5 \\
\hline
\end{tabular}

$C V$ coefficient of variation

${ }^{\text {a }}$ Fortified OF concentration $(\mathrm{ng} / \mathrm{ml})$

calibration curves were $<10 \%$ and the intercept value did not differ significantly from $0(P<0.05)$. For concentrations higher than the LOQ, the variation coefficients of intraday and intermediate precisions were $\leq 15 \%$. The trueness values were within 91.2 and $113 \%$ for the SPE technique and within 98.5 and $114.5 \%$ for the LLE method.

\section{Selectivity, interferences, extraction recovery, and matrix effects}

Oral fluid specimens collected from drug-free individuals showed no interference with the assay. For interferences with minor cannabinoids, CBC was analyzed by infusion in order to determine its ion transitions. As expected, they were identical to those selected for THC and CBD. CBC standards were then injected in the LC-MS/MS. No overlap could be observed. The RT of CBC was 7.24 min while those of THC and CBD were 7.02 and 6.13 min, respectively. This result confirms a previous study of Hazekamp et al. [39]. In 2005, they studied the chromatographic and spectroscopic data of a wide range of cannabinoids. They found that $\mathrm{CBC}, \mathrm{CBD}$, and THC were well separated with a reversed-phase $\mathrm{C} 18$ column whatever the $\mathrm{pH}$ used, acid or basic. More recently, Poklis et al. [40] showed that the RTs of CBC, CBD, and THC were well separated by reversed-phase chromatography. Because $\mathrm{CBC}, \mathrm{CBD}$, and THC are well separated, misidentification of one of these compounds cannot occur. Furthermore, in 1984, BarniComparini et al. [41] studied the cannabinoid levels in 176 plants of different lots of Cannabis sativa L. They showed that $\mathrm{CBC}$ was present only in tiny amounts in the leaves; the maximum concentration was around $0.5 \%$ based on dry weight, suggesting that chromatographic interferences are unlikely.

The extraction efficiencies and matrix effects, expressed as percentages, for each cannabinoid at two concentrations are provided in Tables 4 and 5. Each result is an average of four independent determinations; standard deviations are indicated in brackets. The recovery of cannabinoids was relatively low with the LLE method (approximately $42 \%$ ) and ranged between $39.6 \%$ for THC and $47.1 \%$ for CBN. The extraction yield for all cannabinoids remained relatively constant across the range of concentrations tested. 
Table 3 Validation data for trueness, intraday and intermediate precisions, and linearity for THCCOOH, THCCOOH-gluc, THC-A, THC-gluc, 11-OH-THC, CBD, THC, and CBN obtained using the solid-phase extraction method

\begin{tabular}{|c|c|c|c|c|c|c|c|c|c|}
\hline Validation criterion & Level $^{\mathrm{a}}$ & THCCOOH & $\begin{array}{l}\text { THCCOOH- } \\
\text { gluc }\end{array}$ & THC-A & THC-gluc & $\begin{array}{l}11-\mathrm{OH}- \\
\text { THC }\end{array}$ & $\mathrm{CBD}$ & THC & $\mathrm{CBN}$ \\
\hline \multirow{5}{*}{ Trueness $(\%)$} & 0.5 & 99.7 & 91.2 & 95.5 & 99.0 & 96.7 & 113.0 & 106.4 & 102.7 \\
\hline & 2 & 99.7 & 96.0 & 97.1 & 98.3 & 99.8 & 101.5 & 104.6 & 102.1 \\
\hline & 10 & 100.9 & 95.2 & 98.8 & 97.8 & 101.3 & 98.9 & 102.4 & 102.2 \\
\hline & 30 & 100.1 & 92.0 & 102.5 & 97.9 & 100.2 & 98.2 & 100.8 & 101.1 \\
\hline & 75 & 99.5 & 104.1 & 98.8 & 104.2 & 100.4 & 98.9 & 102.0 & 103.9 \\
\hline \multirow{5}{*}{$\begin{array}{l}\text { Intraday precision } \\
(\mathrm{CV}, \%)\end{array}$} & 0.5 & 6.9 & 4.4 & 8.1 & 4.2 & 5.9 & 9.4 & 7.2 & 3.5 \\
\hline & 2 & 2.4 & 6.0 & 6.1 & 3.6 & 2.4 & 2.8 & 3.4 & 3.9 \\
\hline & 10 & 3.2 & 4.1 & 5.8 & 4.2 & 1.2 & 5.0 & 3.0 & 7.4 \\
\hline & 30 & 1.5 & 5.4 & 3.0 & 5.3 & 0.8 & 5.3 & 1.5 & 2.7 \\
\hline & 75 & 1.7 & 3.8 & 2.7 & 4.2 & 0.8 & 2.4 & 1.4 & 5.2 \\
\hline \multirow{5}{*}{$\begin{array}{l}\text { Intermediate precision } \\
(\mathrm{CV}, \%)\end{array}$} & 0.5 & 5.2 & 20.5 & 9.4 & 6.9 & 10.1 & 12.3 & 5.9 & 6.5 \\
\hline & 2 & 1.4 & 6.3 & 6.0 & 1.5 & 0.4 & 8.4 & 3.8 & 4.3 \\
\hline & 10 & 2.3 & 5.2 & 8.0 & 1.7 & 0.1 & 1.5 & 2.2 & 4.0 \\
\hline & 30 & 0.5 & 5.6 & 4.1 & 3.8 & 0.5 & 2.6 & 1.1 & 2.1 \\
\hline & 75 & 1.5 & 6.0 & 3.4 & 5.4 & 1.1 & 2.1 & 2.2 & 5.0 \\
\hline \multicolumn{10}{|l|}{ Linearity } \\
\hline Slope (CV) & & $\begin{array}{l}0.9965 \\
(1.1 \%)\end{array}$ & $\begin{array}{l}1.0389 \\
(3.6 \%)\end{array}$ & $\begin{array}{l}0.9954 \\
\quad(0.5 \%)\end{array}$ & $\begin{array}{l}1.0197 \\
(2.2 \%)\end{array}$ & $\begin{array}{l}1.000 \\
(0.4 \%)\end{array}$ & $\begin{array}{l}0.9863 \\
\quad(1.9 \%)\end{array}$ & $\begin{array}{l}1.0134 \\
(2.6 \%)\end{array}$ & $\begin{array}{l}1.0025 \\
(1.1 \%)\end{array}$ \\
\hline$y$ intercept $(\mathrm{CV})$ & & $\begin{array}{l}0.0538 \\
\quad(11.1 \%)\end{array}$ & $\begin{array}{r}-0.9038 \\
(5.9 \%)\end{array}$ & $\begin{array}{l}0.0378 \\
(8.1 \%)\end{array}$ & $\begin{array}{r}-0.0350 \\
(6.4 \%)\end{array}$ & $\begin{array}{l}0.0018 \\
(4.8 \%)\end{array}$ & $\begin{array}{l}0.0158 \\
\quad(13.6 \%)\end{array}$ & $\begin{array}{l}0.0751 \\
\quad(5.4 \%)\end{array}$ & $\begin{array}{l}0.0035 \\
\quad(15.5 \%)\end{array}$ \\
\hline$R^{2}$ & & 0.9997 & 0.9967 & 0.9995 & 0.9996 & 0.9999 & 0.9987 & 0.9997 & 0.9994 \\
\hline LOD (ng/ml) & & 0.1 & 0.3 & 0.05 & 0.05 & 0.1 & 0.3 & 0.05 & 0.1 \\
\hline LOQ (ng/ml) & & 0.5 & 1.0 & 0.5 & 0.5 & 0.5 & 0.5 & 0.5 & 0.5 \\
\hline
\end{tabular}

${ }^{a}$ Fortified OF concentration (ng/ml)

However, LLE failed to extract the glucuronide conjugates under all tested conditions. A variety of solvents were evaluated for glucuronide conjugate extraction, including diisopropylether [42] and ethyl acetate:hexane (1:9) acidified with acetic acid [13]. The two latter conditions have been previously used to extract $\mathrm{THCCOOH}$-gluc from urine [42], liver, bile, or kidney [13]. We were unable to replicate these findings with $\mathrm{OF}$. OF contains mucins that form gels, which are responsible for its high viscosity [43]. These glycoproteins and the chemical additives that are present in the extraction buffer of the Quantisal ${ }^{\mathrm{TM}}$ device (blue dye, preservative, detergent) might hamper the LLE extraction of the relatively polar glucuronide derivatives. Although the extraction yields with the SPE method were lower than those of the LLE technique, the SPE represents a good compromise because it allows for the extraction of a wider range of cannabinoids: CBD, THC, its acid precursor (THC-A), its degradation product (CBN), and its primary and secondary metabolites (11-OH-THC and THCCOOH) and their corresponding glucuronide conjugates (THC-gluc and THCCOOH-gluc). Washing of the pad with methanol slightly increased the extraction yield of all cannabinoids (approximately $10 \%$ ).
A matrix effect was observed for all cannabinoids, resulting in an average ion suppression effect of approximately $30 \%$ for SPE and $25 \%$ for LLE. The blue coloring agent that indicates the collection of $1 \mathrm{ml}$ of OF was coextracted with the cannabinoids by the SPE method, whereas it remained in the aqueous phase after LLE. This could explain why the matrix effect of the SPE method exceeded that of the LLE method. The decrease in the signal intensity was the lowest for THC-A and the highest for THC. Concheiro et al. [20] observed a matrix effect of $100 \%$ (ion enhancement) and Badawi et al. [18] found an ion suppression effect of $2.1 \%$ for THC extracted from OF. Although the recovery was relatively low and the matrix effect relatively high, the LOD and LOQ values achieved could be considered excellent to fair for all cannabinoids.

\section{Stability studies and carryover}

The stability of cannabinoids was investigated at room temperature. The Quantisal ${ }^{\mathrm{TM}}$ device pads were spiked with cannabinoids and allowed to remain in the buffer for $1,4,12$, or $24 \mathrm{~h}$ at room temperature prior freezing and 
Table 4 Extraction efficiencies (SD) observed for the LC-MS/MS analysis of eight cannabinoids in spiked drug-free oral fluid samples at different concentrations

\begin{tabular}{|c|c|c|c|c|c|c|}
\hline \multirow[t]{2}{*}{ Analyte } & \multicolumn{2}{|c|}{ SPE extraction efficiency $(\%, n=4)$} & \multicolumn{4}{|c|}{ LLE extraction efficiency $(\%, n=4)$} \\
\hline & $2 \mathrm{ng} / \mathrm{ml}$ & $75 \mathrm{ng} / \mathrm{ml}$ & $100 \mathrm{pg} / \mathrm{ml}$ & $400 \mathrm{pg} / \mathrm{ml}$ & $2 \mathrm{ng} / \mathrm{ml}$ & $75 \mathrm{ng} / \mathrm{ml}$ \\
\hline THCCOOH & $39.8(6.8)$ & $34.2(6.1)$ & $34.9(2.6)$ & $36.7(5.5)$ & $46.7(3.4)$ & $46.5(4.1)$ \\
\hline THCCOOH-gluc & $37.5(3.6)$ & $33.3(4.5)$ & - & - & - & - \\
\hline THC-A & $38.1(7.3)$ & $32.7(6.6)$ & - & - & $44.3(3.5)$ & $40.0(3.0)$ \\
\hline THC-gluc & $41.8(5.0)$ & $37.5(5.8)$ & - & - & - & - \\
\hline 11-OH-THC & $38.3(5.8)$ & $29.5(5.2)$ & - & - & $42.8(1.6)$ & $42.3(2.6)$ \\
\hline CBD & $39.7(8.8)$ & $31.7(6.0)$ & - & - & $44.2(1.2)$ & $42.8(2.9)$ \\
\hline THC & $28.8(8.3)$ & $26.6(5.7)$ & - & - & 39.8 (3.9) & $39.6(2.2)$ \\
\hline CBN & $38.3(7.1)$ & $28.2(3.5)$ & - & - & $43.4(1.2)$ & $47.1(3.0)$ \\
\hline
\end{tabular}

Table 5 Matrix effects (SD) observed for eight cannabinoids in spiked drug-free oral fluid samples at different concentrations

\begin{tabular}{|c|c|c|c|c|c|c|}
\hline \multirow[t]{2}{*}{ Analyte } & \multicolumn{2}{|c|}{ SPE matrix effect (bias $\%, n=4$ ) } & \multicolumn{4}{|c|}{ LLE matrix effect (bias $\%, n=4$ ) } \\
\hline & $2 \mathrm{ng} / \mathrm{ml}$ & $75 \mathrm{ng} / \mathrm{ml}$ & $50 \mathrm{pg} / \mathrm{ml}$ & $400 \mathrm{pg} / \mathrm{ml}$ & $2 \mathrm{ng} / \mathrm{ml}$ & $75 \mathrm{ng} / \mathrm{ml}$ \\
\hline THCCOOH & $-31.4(5.0)$ & $-28.8(5.9)$ & $-33.8(4.7)$ & $-31.6(4.2)$ & $-29.5(3.7)$ & $-21.2(4.1)$ \\
\hline THCCOOH-gluc & $-32.9(4.7)$ & $-29.1(3.3)$ & - & - & - & - \\
\hline THC-A & $-2.4(8.7)$ & $-1.6(6.5)$ & - & - & $-12.1(2.6)$ & $-9.3(1.7)$ \\
\hline THC-gluc & $-19.1(6.8)$ & $-30.3(4.3)$ & - & - & - & - \\
\hline 11-OH-THC & $-32.9(4.4)$ & $-31.0(4.0)$ & - & - & $-21.1(3.4)$ & $-22.1(2.9)$ \\
\hline CBD & $-29.6(5.2)$ & $-41.5(3.5)$ & - & - & $-25.5(3.1)$ & $-29.1(1.8)$ \\
\hline THC & $-45.5(4.1)$ & $-53.1(5.2)$ & - & - & $-38.9(4.6)$ & $-39.3(2.3)$ \\
\hline CBN & $-49.0(4.6)$ & $-39.7(7.1)$ & - & - & $-32.5(4.7)$ & $-31.8(3.8)$ \\
\hline
\end{tabular}

Negative values indicate ion suppression, whereas positive values indicate ion enhancement

storing at $-80{ }^{\circ} \mathrm{C}$. No obvious variation $(<15 \%)$ in the peak area was observed over this time period. These results demonstrate that cannabinoids are relatively stable in the extraction buffer and that it is not necessary to incubate the pad at room temperature for at least $4 \mathrm{~h}$, as recommended by the manufacturer for optimal cannabinoid extraction.

The stability of the cannabinoids after one or three freeze-thaw cycles was also investigated. OF extracts were injected into the LC-MS/MS system after one or three freeze-thaw cycles, and the peak areas were compared to those of samples analyzed immediately after spiking and without any freezing. All cannabinoids were stable after one freeze-thaw cycle, with the exception of $\mathrm{THCCOOH}-$ gluc and CBN (exhibiting 17 and $13 \%$ maximum loss, respectively). In contrast, three freeze-thaw cycles resulted in a considerable degradation of cannabinoids, with a mean decrease of $30 \%$ and a maximum loss of $52 \%$ for CBN.

Analyses of authentic oral fluid samples

Data for the appearance and disappearance of cannabinoids as a function of time in neat $\mathrm{OF}$ collected at home with the Quantisal $^{\mathrm{TM}}$ device are provided in Table 6. The LLE method was used for the determination of $\mathrm{THCCOOH}$, whereas SPE was used for the analysis of all other cannabinoids. We detected THC at very high concentrations, up to $11,887 \mathrm{ng} / \mathrm{ml}$ for subject 5 , in the first OF specimens obtained $10 \mathrm{~min}$ after the first inhalation of cannabis smoke. All samples tested positive for THC at concentrations in the range $2.8-128 \mathrm{ng} / \mathrm{ml}$ in the final OF specimen. THC-A was also detected at relatively high levels with peak concentrations ranging from 44 to $2031 \mathrm{ng} / \mathrm{ml}$. As observed with THC, all OF specimens tested positive for THC-A. Interestingly, THC and THC-A exhibited the highest concentrations in the first sample obtained $10 \mathrm{~min}$ after inhalation. These results indicate that THC-A is not completely transformed into THC by decarboxylation during the smoking process, and it is also present in $\mathrm{OF}$ primarily as a result of deposition in the oral cavity. CBD and CBN were also found, but in much lower concentrations. The time to reach the maximum level for $\mathrm{CBD}$ and CBN was identical to that of THC and THC-A, suggesting that their presence is also mainly due to the contamination of the oral cavity during the inhalation. THCCOOH was only detected in a few OF samples, and always at very low concentrations. In contrast to the other cannabinoids, the 
time to reach its maximum level was delayed in four out of five cases, from the first to the second, and even to the fourth $\mathrm{OF}$ specimen taken after smoking. Because THC$\mathrm{COOH}$ is not known to be present in the joints and only produced by animal metabolism, and also because its kinetic in OF differs from other cannabinoids found in cannabis, its presence is thought to result exclusively from body metabolism. The low concentrations of THCCOOH could only be measured using the LLE method. The concentrations ranged from the LOQ $(80 \mathrm{pg} / \mathrm{ml})$ to $2.4 \mathrm{ng} / \mathrm{ml}$. The LOD and LOQ of the SPE method were not high enough to detect and measure this metabolite in the majority of OF samples. Surprisingly, the more polar glucuronide conjugates were not found in the OF specimens of the five cannabis smokers, except for the first volunteer for whom traces of THCCOOH-gluc were found in three out of seven samples. Several hypotheses can be presented to explain these observations: a strong binding to plasma proteins [44], poor diffusion into OF [45], a lack of transport proteins, or the presence of degrading enzymes. In the latter case, the presence of beta-glucuronidase enzymes in OF [35-37] could explain the lack of detection of THCCOOH-gluc and THC-gluc in OF. In agreement with the assumption that glucuronide conjugates of cannabinoids are present in OF in significant amounts, a study published in 2007 by Moore et al. [4] suggests that $48.2 \%$ of $\mathrm{THCCOOH}$ is glucuronidated in OF (estimated after beta-glucuronidase treatment). In the same study, the authors indicate that the concentration of THC in OF remained nearly unchanged after treatment with betaglucuronidase. This result suggests that THC was poorly conjugated at best. Similar observations were made with the glucuronide conjugates of other drugs. For example, oxazepam glucuronide and other benzodiazepine conjugates were found only in trace levels in OF [46]. A minor but active THC metabolite, 11-OH-THC was also not detected.

Assessment of chemical and enzymatic hydrolysis of glucuronide conjugates of THC and $\mathrm{THCCOOH}$ in oral fluid

The extent of hydrolysis of THC and THCCOOH glucuronides and the resulting formation of free cannabinoids were investigated under various incubation conditions. These conditions were selected to distinguish between nonenzymatic and enzyme-catalyzed degradation of glucuronidated cannabinoids. To assess the nonenzymatic hydrolysis of conjugates, we incubated glucuronides in the presence of heat-inactivated OF enzymes. We also investigated the extent of total hydrolysis (both uncatalyzed and enzymatic) by incubating the glucuronides with an untreated OF mix. The reaction media were diluted with
Table 6 Cannabinoid concentration in oral fluid as a function of time before and after smoking a homemade joint

\begin{tabular}{|c|c|c|c|c|c|c|}
\hline Subject & $\begin{array}{l}\text { Time } \\
(\mathrm{min})\end{array}$ & THCCOOH & $\begin{array}{l}\text { THC- } \\
\text { A }\end{array}$ & CBD & THC & $\mathrm{CBN}$ \\
\hline \multirow[t]{6}{*}{1} & -10 & 0.5 & 2.6 & 0.5 & 290 & 6.7 \\
\hline & 20 & 1.3 & 175 & 6.9 & 3120 & 165 \\
\hline & 40 & 2.4 & 41 & 4.3 & 1970 & 98 \\
\hline & 60 & 0.7 & 10 & 0.6 & 441 & 19 \\
\hline & 120 & 0.3 & 12 & n.d. & 232 & 6.4 \\
\hline & 210 & 0.4 & 6.6 & n.d. & 30 & 11 \\
\hline \multirow[t]{6}{*}{2} & -10 & n.d. & 2.7 & n.d. & 5.9 & n.d. \\
\hline & 20 & 0.17 & 66 & 3.7 & 971 & 182 \\
\hline & 40 & 0.31 & 14 & 1.2 & 210 & 45 \\
\hline & 60 & $<0.08$ & 2.2 & 0.9 & 37 & 2.8 \\
\hline & 120 & $<0.08$ & 1.7 & n.d. & 33 & 2.7 \\
\hline & 210 & n.d. & $<0.5$ & n.d. & 22 & 2.0 \\
\hline \multirow[t]{6}{*}{3} & -10 & n.d. & 1.0 & n.d. & 1.4 & 0.5 \\
\hline & 20 & 0.17 & 44 & 2.8 & 1060 & 212 \\
\hline & 40 & 0.14 & 10 & 2.1 & 627 & 37 \\
\hline & 60 & $<0.08$ & 6.1 & 1.5 & 123 & 31 \\
\hline & 120 & n.d. & 1.0 & $<0.5$ & 9 & 4.2 \\
\hline & 210 & n.d. & 0.7 & n.d. & 7 & 3.9 \\
\hline \multirow[t]{6}{*}{4} & -10 & n.d. & 15 & $<0.5$ & 13 & $<0.5$ \\
\hline & 20 & n.d. & 45 & 7.3 & 196 & 4.3 \\
\hline & 40 & 0.51 & 19 & 2.5 & 84 & 1.8 \\
\hline & 60 & 0.35 & 6.8 & $<0.5$ & 13 & 3.1 \\
\hline & 120 & 0.08 & 6.1 & $<0.5$ & 8.2 & 2.4 \\
\hline & 210 & n.d. & 5.6 & n.d. & 2.8 & $<0.5$ \\
\hline \multirow[t]{7}{*}{5} & -10 & n.d. & 279 & n.d. & 475 & 2.5 \\
\hline & 10 & n.d. & 2031 & 5.0 & 11,887 & 79 \\
\hline & 20 & $<0.08$ & 692 & 2.1 & 2858 & 44 \\
\hline & 40 & 0.15 & 353 & $<0.5$ & 1041 & 10 \\
\hline & 60 & 0.31 & 763 & n.d. & 1396 & 8.3 \\
\hline & 120 & 0.18 & 436 & n.d. & 729 & 5.7 \\
\hline & 300 & $<0.08$ & 158 & n.d. & 128 & 0.8 \\
\hline
\end{tabular}

Concentrations of cannabinoids in neat oral fluid are expressed in $\mathrm{ng} / \mathrm{ml}$

either water or an acetate buffer known to be optimal for beta-glucuronidase activity. The relative concentrations of substrates and products after $0,0.5,1$, and $5 \mathrm{~h}$ are provided in Table 7. A significant hydrolysis of THCCOOH-gluc $(\sim 85 \%$ after $5 \mathrm{~h})$ was only observed with native OF. THC-gluc was only mildly degraded $(<30 \%)$, suggesting that this compound is much more resistant toward human beta-glucuronidase action. This latter result confirms a previous study of Watanabe et al. [47]. They demonstrated that $\Delta^{8}$-THC-gluc is relatively resistant to degradation with a maximum hydrolysis of $31.6 \%$ with bacterial betaglucuronidase. Furthermore, Scheidweiler et al. [48] demonstrated recently that in urine THC-gluc is more stable than THCCOOH-gluc. Conversely, the decrease in the substrate 
Table 7 Comparison of cannabinoid glucuronide degradation in native and inactivated oral fluid (OF) as well as in aqueous and buffered $(\mathrm{pH} 4.5)$ solutions

\author{
Concentrations of THCCOOH, \\ THCCOOH-gluc, THC and \\ THC-gluc are expressed in \\ $\mathrm{pmol} / \mathrm{ml}$ of reaction mixture \\ -, not available
}

\begin{tabular}{|c|c|c|c|c|c|}
\hline Sample & Time (h) & THCCOOH & THCCOOH-gluc & THC & THC-gluc \\
\hline \multirow[t]{4}{*}{$\mathrm{OF}+$ water } & 0 & 2.13 & 10.11 & 0.40 & 9.19 \\
\hline & 0.5 & 2.43 & 8.37 & 2.27 & 8.34 \\
\hline & 1 & 3.93 & 5.60 & 2.97 & 7.46 \\
\hline & 5 & 7.94 & 1.50 & - & 6.71 \\
\hline \multirow[t]{4}{*}{$\mathrm{OF}+$ acetate buffer } & 0 & 1.45 & 10.48 & 0.55 & 8.88 \\
\hline & 0.5 & 2.62 & 8.82 & 0.79 & 8.03 \\
\hline & 1 & 4.05 & 6.43 & 1.94 & 7.78 \\
\hline & 5 & 7.35 & 2.01 & - & 7.48 \\
\hline \multirow{4}{*}{ Inactivated $\mathrm{OF}+$ water } & 0 & 0.90 & 10.51 & 0.45 & 8.79 \\
\hline & 0.5 & 0.86 & 10.09 & 0.34 & 8.45 \\
\hline & 1 & 0.90 & 9.68 & 0.38 & 8.30 \\
\hline & 5 & 0.92 & 7.00 & 0.39 & 8.24 \\
\hline \multirow[t]{4}{*}{ Inactivated $\mathrm{OF}+$ acetate buffer } & 0 & 0.65 & 10.95 & 0.43 & 8.76 \\
\hline & 0.5 & 0.53 & 10.67 & 0.40 & 7.95 \\
\hline & 1 & 0.54 & 10.91 & 0.36 & 8.19 \\
\hline & 5 & 0.42 & 11.20 & 0.39 & 8.17 \\
\hline \multirow[t]{4}{*}{ Water + water } & 0 & $<\mathrm{LOQ}$ & 8.73 & $<\mathrm{LOQ}$ & 3.14 \\
\hline & 0.5 & $<\mathrm{LOQ}$ & 7.96 & $<\mathrm{LOQ}$ & 3.03 \\
\hline & 1 & $<\mathrm{LOQ}$ & 6.30 & $<\mathrm{LOQ}$ & 3.09 \\
\hline & 5 & $<\mathrm{LOQ}$ & 5.86 & $<\mathrm{LOQ}$ & 3.02 \\
\hline \multirow[t]{4}{*}{ Water + acetate buffer } & 0 & $<\mathrm{LOQ}$ & 8.49 & $<\mathrm{LOQ}$ & 3.31 \\
\hline & 0.5 & $<\mathrm{LOQ}$ & 5.85 & $<\mathrm{LOQ}$ & 3.37 \\
\hline & 1 & $<\mathrm{LOQ}$ & 5.48 & $<\mathrm{LOQ}$ & 3.49 \\
\hline & 5 & $<\mathrm{LOQ}$ & 5.45 & $<\mathrm{LOQ}$ & 3.07 \\
\hline
\end{tabular}

concentration coincided with a substantial increase in $\mathrm{THCCOOH}$ and in THC. The buffering of the reaction medium significantly increased the extent of glucuronide degradation. The enzymatic degradation of $\mathrm{THCCOOH}-$ gluc increased from $5.1 \mathrm{pmol}$ in $\mathrm{OF}+$ water to $8.5 \mathrm{pmol}$ in $\mathrm{OF}+$ buffer for $1.0 \mathrm{ml}$ of $\mathrm{OF}$ volume (i.e., a $67 \%$ increase). Under various conditions, the absence of native $\mathrm{OF}$ in the reaction medium significantly diminished the hydrolysis of glucuronides. OF proteins and their conformation (native or denaturated) certainly have a significant influence on the stability and extractability of cannabinoids. In addition to mucins and enzymes, OF contains many proteins including albumin. According to Wang et al. [49], human albumin exists in a wide range of concentrations in saliva (5-45 mg/l). In 2002, Skopp et al. [44] showed that the addition of albumin in protein-free samples prior to the extraction step increases the recovery of free and conjugated cannabinoids. Furthermore, this protein is known to bind with the majority of the cannabinoids [50]. The binding of cannabinoids to albumin and other proteins could stabilize and protect glucuronide conjugates from degradation. Finally, the $\mathrm{pH}$ of the incubation medium should also have an influence. Indeed the chemical hydrolysis of glucuronides is enhanced at $\mathrm{pH} 7$ (inactivated
$\mathrm{OF}+$ water) compared to $\mathrm{pH} 4.5$ (inactivated $\mathrm{OF}+$ acetate buffer). Based on the comparison of the extent of THCCOOH-gluc degradation after incubation with native or inactivated OF, we can assume that approximately $60 \%$ of the THCCOOH-gluc was enzymatically degraded, whereas only $40 \%$ was chemically hydrolyzed. These results confirm the presence of beta-glucuronidase activity in OF, and may partly explain the difficulty to detect glucuronide conjugates in this matrix. THC-gluc was found to be much less susceptible to enzymatic hydrolysis than THCCOOH-gluc, which contains a more labile ester bond.

\section{Conclusions}

To our knowledge, this work represents the first analytical method developed for the detection and quantification of a broad range of cannabinoids, including a THC precursor and two glucuronide conjugates, in oral fluid by LC-MS/ MS. This method utilizes a new Kinetex $^{\mathrm{TM}}$ core-shell column combined with an API $5000^{\mathrm{TM}}$ triple quadrupole system, and was successfully applied for the determination of cannabinoids in OF specimens collected from five different cannabis smokers. The collection of the OF was 
simplified with the use of a Quantisal ${ }^{\mathrm{TM}}$ collection device. THC-gluc was not detected in real OF specimens, whereas $\mathrm{THCCOOH}$-gluc was found only at trace levels in a few samples. Moreover, our experiments suggest that THC$\mathrm{COOH}$-glucuronide could be hydrolyzed by beta-glucuronidase enzymes present in the $\mathrm{OF}$. Liquid-liquid extraction proved to be the most efficient method for $\mathrm{THCCOOH}$ detection provided that $\mathrm{THCCOOH}$-glucuronide and THC-glucuronide determination is not required.

Acknowledgments The authors thank the Swiss National Science Foundation (FNS_320030_127507/1) and the Faculty of Biology and Medicine (interdisciplinary grant) at the University of Lausanne for their financial support.

\section{References}

1. Kelly E, Darke S, Ross J (2004) A review of drug use and driving: epidemiology, impairment, risk factors and risk perceptions. Drug Alcohol Rev 23(3):319-344. doi:10.1080/095952 30412331289482

2. Choo RE, Huestis MA (2004) Oral fluid as a diagnostic tool. Clin Chem Lab Med 42(11):1273-1287. doi:10.1515/CCLM.2004.248

3. Molnar A, Lewis J, Doble P, Hansen G, Prolov T, Fu S (2011) A rapid and sensitive method for the identification of delta-9-tetrahydrocannabinol in oral fluid by liquid chromatography-tandem mass spectrometry. Forensic Sci Int. doi:10.1016/j.forsciint. 2011.01.045

4. Moore C, Rana S, Coulter C, Day D, Vincent M, Soares J (2007) Detection of conjugated 11-nor-Delta9-tetrahydrocannabinol-9carboxylic acid in oral fluid. J Anal Toxicol 31(4):187-194

5. Lee D, Milman G, Barnes AJ, Goodwin RS, Hirvonen J, Huestis MA (2011) Oral fluid cannabinoids in chronic, daily Cannabis smokers during sustained, monitored abstinence. Clin Chem 57(8):1127-1136. doi:10.1373/clinchem.2011.164822

6. Milman G, Barnes AJ, Schwope DM, Schwilke EW, Darwin WD, Goodwin RS, Kelly DL, Gorelick DA, Huestis MA (2010) Disposition of cannabinoids in oral fluid after controlled around-theclock oral THC administration. Clin Chem 56(8):1261-1269. doi: 10.1373/clinchem.2009.141853

7. Milman G, Schwope DM, Schwilke EW, Darwin WD, Kelly DL, Goodwin RS, Gorelick DA, Huestis MA (2011) Oral fluid and plasma cannabinoid ratios after around-the-clock controlled oral Delta(9)-tetrahydrocannabinol administration. Clin Chem 57(11):1597-1606. doi:10.1373/clinchem.2011.169490

8. Moore C, Rana S, Coulter C (2007) Simultaneous identification of 2-carboxy-tetrahydrocannabinol, tetrahydrocannabinol, cannabinol and cannabidiol in oral fluid. J Chromatogr B Analyt Technol Biomed Life Sci 852(1-2):459-464. doi:10.1016/ j.jchromb.2007.02.016

9. Coles R, Clements TT, Nelson GJ, McMillin GA, Urry FM (2005) Simultaneous analysis of the Delta9-THC metabolites 11-nor-9-carboxy-Delta9-THC and 11-hydroxy-Delta9-THC in meconium by GC-MS. J Anal Toxicol 29(6):522-527

10. ElSohly MA, Feng S (1998) Delta 9-THC metabolites in meconium: identification of 11-OH-delta 9-THC, 8 beta, 11-diOHdelta 9-THC, and 11-nor-delta 9-THC-9-COOH as major metabolites of delta 9-THC. J Anal Toxicol 22(4):329-335

11. Fabritius M, Staub C, Mangin P, Giroud C (2012) Distribution of free and conjugated cannabinoids in human bile samples. Forensic Sci Int. http://dx.doi.org/10.1016/j.forsciint.2012.08.013
12. Feng S, ElSohly MA, Salamone S, Salem MY (2000) Simultaneous analysis of delta9-THC and its major metabolites in urine, plasma, and meconium by GC-MS using an immunoaffinity extraction procedure. J Anal Toxicol 24(6):395-402

13. Gronewold A, Skopp G (2011) A preliminary investigation on the distribution of cannabinoids in man. Forensic Sci Int 210(1-3):e7-e11. doi:10.1016/j.forsciint.2011.04.010

14. Lin DL, Lin RL (2005) Distribution of 11-nor-9-carboxy-Delta9tetrahydrocannabinol in traffic fatality cases. J Anal Toxicol 29(1):58-61

15. Marchei E, Pellegrini M, Pacifici R, Palmi I, Lozano J, GarciaAlgar O, Pichini S (2006) Quantification of Delta9-tetrahydrocannabinol and its major metabolites in meconium by gas chromatographic-mass spectrometric assay: assay validation and preliminary results of the "meconium project". Ther Drug Monit 28(5):700-706. doi:10.1097/01.ftd.0000245380.95186.13

16. Moore C, Lewis D, Becker J, Leikin J (1996) The determination of 11-nor-delta 9-tetrahydrocannabinol-9-carboxylic acid (THC$\mathrm{COOH}$ ) in meconium. J Anal Toxicol 20(1):50-51

17. Papoutsis I, Nikolaou P, Dona A, Pistos C, Stefanidou M, Spiliopoulou C, Athanaselis S (2012) A validated GC-MS method for the determination of $\Delta 9$-tetrahydrocannabinol and 11-nor- $\Delta 9$ tetrahydrocannabinol-9-carboxylic acid in bile samples. Forensic Toxicol 30(1):51-58. doi:10.1007/s11419-011-0126-1

18. Badawi N, Simonsen KW, Steentoft A, Bernhoft IM, Linnet K (2009) Simultaneous screening and quantification of 29 drugs of abuse in oral fluid by solid-phase extraction and ultraperformance LC-MS/MS. Clin Chem 55 (11):2004-2018. doi:10.1373/ clinchem.2008.122341

19. Chi E, Cole J (2010) Detecting Marijuana in Saliva. Forensic Mag 7(5):17-20

20. Concheiro M, de Castro A, Quintela O, Cruz A, Lopez-Rivadulla M (2008) Determination of illicit and medicinal drugs and their metabolites in oral fluid and preserved oral fluid by liquid chromatography-tandem mass spectrometry. Anal Bioanal Chem 391(6):2329-2338. doi:10.1007/s00216-008-2135-4

21. Day D, Kuntz DJ, Feldman M, Presley L (2006) Detection of THCA in oral fluid by GC-MS-MS. J Anal Toxicol 30(9): 645-650

22. Laloup M, Ramirez Fernandez Mdel M, Wood M, De Boeck G, Henquet C, Maes V, Samyn N (2005) Quantitative analysis of delta9-tetrahydrocannabinol in preserved oral fluid by liquid chromatography-tandem mass spectrometry. J Chromatogr A 1082(1):15-24

23. Niedbala RS, Kardos KW, Fritch DF, Kardos S, Fries T, Waga J, Robb J, Cone EJ (2001) Detection of marijuana use by oral fluid and urine analysis following single-dose administration of smoked and oral marijuana. J Anal Toxicol 25(5):289-303

24. Oiestad EL, Johansen U, Christophersen AS (2007) Drug screening of preserved oral fluid by liquid chromatography-tandem mass spectrometry. Clin Chem 53(2):300-309. doi: 10.1373/clinchem.2006.074237

25. Quintela O, Andrenyak DM, Hoggan AM, Crouch DJ (2007) A validated method for the detection of Delta 9-tetrahydrocannabinol and 11-nor-9-carboxy- Delta 9-tetrahydrocannabinol in oral fluid samples by liquid chromatography coupled with quadrupole-time-of-flight mass spectrometry. $\mathbf{J}$ Anal Toxicol 31(3): 157-164

26. Sergi M, Bafile E, Compagnone D, Curini R, D'Ascenzo G, Romolo FS (2009) Multiclass analysis of illicit drugs in plasma and oral fluids by LC-MS/MS. Anal Bioanal Chem 393(2):709-718. doi:10.1007/s00216-008-2456-3

27. Simoes SS, Ajenjo AC, Franco JM, Vieira DN, Dias MJ (2009) Liquid chromatography/tandem mass spectrometry for the qualitative and quantitative analysis of illicit drugs and medicines in 
preserved oral fluid. Rapid Commun Mass Spectrom 23(10):1451-1460. doi:10.1002/rcm.4020

28. Simonin J, Salquebre G, Cirimele V, Kintz P (2007) Screening for illicit drugs in oral fluid by LC-MS/MS. Ann Toxicol Anal 19(2):141-150

29. Gritti F, Guiochon G (2010) Performance of columns packed with the new shell Kinetex-C18 particles in gradient elution chromatography. J Chromatogr A 1217(10):1604-1615. doi:10.1016/j.chroma. 2010.01.008

30. Gritti F, Leonardis I, Shock D, Stevenson P, Shalliker A, Guiochon G (2010) Performance of columns packed with the new shell particles, Kinetex-C18. J Chromatogr A 1217(10):15891603. doi:10.1016/j.chroma.2009.12.079

31. Moore C, Vincent M, Rana S, Coulter C, Agrawal A, Soares J (2006) Stability of Delta(9)-tetrahydrocannabinol (THC) in oral fluid using the Quantisal collection device. Forensic Sci Int 164(2-3):126-130. doi:10.1016/j.forsciint.2005.12.011

32. Hubert P, Nguyen-Huu JJ, Boulanger B, Chapuzet E, Chiap P, Cohen N, Compagnon PA, Dewe W, Feinberg M, Lallier M, Laurentie M, Mercier N, Muzard G, Nivet C, Valat L, Rozet E (2007) Harmonization of strategies for the validation of quantitative analytical procedures. A SFSTP proposal-part II. J Pharm Biomed Anal 45(1):70-81. doi:10.1016/j.jpba.2007.06.013

33. Hubert P, Nguyen-Huu JJ, Boulanger B, Chapuzet E, Cohen N, Compagnon PA, Dewe W, Feinberg M, Laurentie M, Mercier N, Muzard G, Valat L, Rozet E (2007) Harmonization of strategies for the validation of quantitative analytical procedures. A SFSTP proposal-part III. J Pharm Biomed Anal 45(1):82-96. doi: 10.1016/j.jpba.2007.06.032

34. Matuszewski BK, Constanzer ML, Chavez-Eng CM (2003) Strategies for the assessment of matrix effect in quantitative bioanalytical methods based on HPLC-MS/MS. Anal Chem 75(13):3019-3030

35. Chauncey HH, Lionetti F, Winer RA, Lisanti VF (1954) Enzymes of human saliva. I. The determination, distribution, and origin of whole saliva enzymes. J Dent Res 33(3):321-334

36. Ghadge MS, Raste AS (2006) Place of salivary beta glucuronidase activity in head and neck cancers. Indian J Clin Biochem 21(1):196-198

37. Lamster IB, Kaufman E, Grbic JT, Winston LJ, Singer RE (2003) Beta-glucuronidase activity in saliva: relationship to clinical periodontal parameters. J Periodontol 74(3):353-359. doi: 10.1902/jop.2003.74.3.353

38. Pil K, Verstraete A (2008) Current developments in drug testing in oral fluid. Ther Drug Monit 30(2):196-202. doi:10.1097/ FTD.0b013e318167d563

39. Hazekamp A, Peltenburg A, Verpoorte R, Giroud C (2005) Chromatographic and spectroscopic data of cannabinoids from
Cannabis sativa L. J Liq Chromatogr Relat Technol 28(15): 2361-2382

40. Poklis JL, Thompson CC, Long KA, Lichtman AH, Poklis A (2010) Disposition of cannabichromene, cannabidiol, and Delta(9)-tetrahydrocannabinol and its metabolites in mouse brain following marijuana inhalation determined by high-performance liquid chromatography-tandem mass spectrometry. J Anal Toxicol 34(8):516-520

41. Barni-Comparini I, Ferri S, Centini F (1984) Cannabinoid level in the leaves as a tool for the early discrimination of cannabis chemiovariants. Forensic Sci Int 24(1):37-42

42. Skopp G, Potsch L (2002) Stability of 11-nor-delta(9)-carboxytetrahydrocannabinol glucuronide in plasma and urine assessed by liquid chromatography-tandem mass spectrometry. Clin Chem 48(2):301-306

43. Humphrey SP, Williamson RT (2001) A review of saliva: normal composition, flow, and function. J Prosthet Dent 85(2):162-169. doi:10.1067/mpr.2001.113778

44. Skopp G, Potsch L, Mauden M, Richter B (2002) Partition coefficient, blood to plasma ratio, protein binding and short-term stability of 11-nor-Delta(9)-carboxy tetrahydrocannabinol glucuronide. Forensic Sci Int 126(1):17-23

45. Cone EJ, Huestis MA (2007) Interpretation of oral fluid tests for drugs of abuse. Ann N Y Acad Sci 1098:51-103. doi:10.1196/ annals. 1384.037

46. Smink BE, Hofman BJ, Dijkhuizen A, Lusthof KJ, de Gier JJ, Egberts AC, Uges DR (2008) The concentration of oxazepam and oxazepam glucuronide in oral fluid, blood and serum after controlled administration of 15 and $30 \mathrm{mg}$ oxazepam. Br J Clin Pharmacol 66(4):556-560. doi:10.1111/j.1365-2125.2008.03252.x

47. Watanabe K, Oguri K, Yoshimura H (1979) Synthesis of delta 8-tetrahydrocannabinol glucuronide and sulfate, and their metabolic disposition in rats. Chem Pharm Bull 27(12):3009-3014

48. Scheidweiler KB, Desrosiers NA, Huestis MA (2012) Simultaneous quantification of free and glucuronidated cannabinoids in human urine by liquid chromatography tandem mass spectrometry. Clin Chim Acta Int J Clin Chem 413(23-24):1839-1847. doi:10.1016/j.cca.2012.06.034

49. Wang RE, Tian L, Chang YH (2012) A homogeneous fluorescent sensor for human serum albumin. J Pharm Biomed Anal 63:165-169. doi:10.1016/j.jpba.2011.12.035

50. Fanali G, Cao Y, Ascenzi P, Trezza V, Rubino T, Parolaro D, Fasano M (2011) Binding of delta9-tetrahydrocannabinol and diazepam to human serum albumin. IUBMB Life 63(6):446-451. doi:10.1002/iub.466 